\title{
Achievement of the Vacuum System of Taiwan Photon Source*
}

\author{
Gao-Yu HSIUNG*1 \\ ${ }^{*}$ National Synchrotron Radiation Research Center, 101 Hsin-Ann Road, Hsinchu Science Park, Hsinchu 30076, Taiwan
}

(Received June 3, 2016, Accepted August 25, 2016)

Commissioning of Taiwan Photon Source (TPS), a 3-GeV synchrotron light source, began in 2014 summer, observed the first light on 2014 December 31, and achieved in three months the primary goals of low emittance $\sim 1.6 \mathrm{~nm}$ rad at beam current $100 \mathrm{~mA}$ with lifetime $6 \mathrm{~h}$ and top-up operation. The dynamic pressure $1.2 \times 10^{-9} \mathrm{~Pa} \mathrm{~mA}^{-1}$ at accumulated beam dose $33 \mathrm{~A} \mathrm{~h}$ after beam cleaning and a measured broadband impedance about $0.12 \Omega$ reflects the satisfactory vacuum performance of this electron-storage ring. The implementation of ultrahigh-vacuum systems (aluminium, length $14 \mathrm{~m}$ ) constructed for the 24 arccells of TPS involved numerically controlled precise machining free of oil in an ethanol environment, cleaning with ozonized water, automatic TIG welding of aluminium chambers (large, $4 \mathrm{~m}$ ), assembly of vacuum systems (aluminium, full length $14 \mathrm{~m}$ ) in the clean room, baking to ultrahigh vacuum ex situ before installation, and rapid loading of the 14-m vacuum cells into the TPS tunnel with hangers for carriage and transport; associated with the engineering developments are key technologies to achieve the high quality of the ultrahigh-vacuum systems for the electron-storage ring of this accelerator light source.

\section{Introduction}

Taiwan Photon Source (TPS) is a third-generation synchrotron light source of energy $3 \mathrm{GeV}$. The design of 24 double-bend achromatic (DBA) lattices that comprises 24 unit cells of arc section and 24 straight sections accommodating further insertion devices constitutes an electron-storage ring of circumference $518.4 \mathrm{~m}$ and generates a natural beam emittance less than $1.6 \mathrm{~nm}$ rad with consequently more brilliant synchrotron light ${ }^{1)}$. The construction of TPS began in 2007 and installation was completed in 2014. Commissioning of TPS was initiated in 2014 summer, beginning with beam injection from the $150-\mathrm{MeV}$ LINAC, energy ramping to $3 \mathrm{GeV}$ in the booster ring (BR), and extraction of the beam to the storage ring (SR), which yielded the first synchrotron light on 2014 December 31. During the next three months, further commissioning in 2015 spring raised the beam current to $100 \mathrm{~mA}$ with a top-up operational mode of lifetime $6 \mathrm{~h}$ and attained the objective of emittance $<1.6 \mathrm{~nm} \mathrm{rad}^{2}$. After confirmation that the overall system of TPS operated without significant problem, TPS was shut down for 6.5 months for replacement of two RF cavities with superconducting ones, installing ten insertion devices (ID) and the corresponding beam lines (BL) and front ends (FE). Subsequent development raised the beam current above $200 \mathrm{~mA}$ in one month after that shutdown.

The vacuum system for the electron storage ring was designed to achieve the highest performance with respect to vacuum, reliability and stability. The major issues or problems arose from the scattering of residual gases with the electron beam and the impact of wake fields and broad-band impedance from the beam duct to the bunched beam that resulted in beam loss and instability.

* Presented as an invited talk at the $56^{\text {th }}$ annual symposium of the Vacuum Society of Japan, December 3, 2015.
Since limitation of the beam-life time (Tau) associated with the residual gases is dominant by the inelastic Bremsstrahlung scattering which is proportional to the radiation length $(X o)$ divided by mass $(M)$ of the gas and inverse proportional to the pressure $(P)$, as shown in the equation below ${ }^{3)}$,

$$
\text { Tau }=3.210^{-8} \mathrm{Xo}^{-1} \mathrm{P}^{-1}
$$

In case of $\mathrm{CO}_{2}$ gas, $\mathrm{Xo} M^{-1}=0.82$, then

$$
\begin{array}{r}
P \sim 2.610^{-8} \mathrm{Tau}^{-1} \\
\text { or } \quad P<1.310^{-9} \text { Torr }\left(\sim 1.710^{-7} \mathrm{~Pa}\right) \\
\quad(\text { if } \mathrm{Tau}>20 \text { hours }) .
\end{array}
$$

Then the criteria of the pressure in the beam ducts must be lower than $170 \mathrm{nPa}$ to maintain the gaseous life time longer than 20 hours. To mitigate the beam scattering from residual gases, large aluminium bending chambers (length about $4 \mathrm{~m}$ ) manufactured with a process completely free of oil were adopted for the vacuum system of TPS; the criterion of precision was set to be about 0.1 $\mathrm{mm}$ for the critical parts ${ }^{4,5}$. The overall design of the ultrahigh-vacuum (UHV) system benefited from the experience of the UHV technologies acquired from the construction and operation of Taiwan Light Source $(\mathrm{TLS}, 1.5 \mathrm{GeV})^{6}$. The concept of manufacturing an arccell UHV system (aluminium, full length $14 \mathrm{~m}$ ) was thus formed $^{7)}$. To confirm the key techniques to be applied, a prototype vacuum system (arc-cell aluminium, $14 \mathrm{~m}$ ) was constructed to prove the specifications ${ }^{8}$. Several innovative techniques including the $\mathrm{CNC}$ machining with ethanol ${ }^{7)}$, cleaning with ozonized water ${ }^{9)}$, a six-torch TIG auto-welding system and beam position monitor (BPM) with a small reflection ratio ${ }^{10)}$, were developed to fulfill the specific requirements. The critical vacuum components of low-impedance design and oil-free manufacturing are described in the following sections. The achievement and the results of the commissioning of the TPS vacuum systems are also addressed. 


\section{Low-impedance design of the TPS vacuum system}

Figure 1 depicts a partial layout of the TPS electronstorage ring that contains a straight section and arc-cell sections of the 24-DBA lattice. The lattice magnets in the arc cell $(14 \mathrm{~m})$ are tightly assembled. The vacuum chambers were fitted inside the magnets with clearance $\sim 3$ $\mathrm{mm}$ between the magnetic poles or coils and the chambers ${ }^{7}$. Figure 2 presents a schematic drawing of a typical $14-\mathrm{m}$ arc-cell vacuum system that is composed of two short straight (S-) chambers, S3 and S4, and two bending (B-) chambers, B1 and B2. The four chambers are made of aluminium alloys and welded in series S3B1-S4-B2 to one section. The B-chambers (aluminium alloy A6061T651, length about $4 \mathrm{~m}$ ) were precisely machined and welded to a precision better than $0.3 \mathrm{~mm}$. The S-chambers (made of aluminium A6063T5 extrusion) were welded with the BPM ducts and the pumping chambers. The overall precision of the alignment for the 14-m-cell vacuum chambers was maintained within 0.3 $\mathrm{mm}$. To tolerate the misalignment of the chambers, only two bellows are welded, between S3-B1 and between S4B2. Two flanges were welded on both ends of the 14-m cell to connect the sector gate valves (SGV). One crotch absorber was installed in the antechamber of each of B1 and $\mathrm{B} 2$; located $\sim 2.4 \mathrm{~m}$ downstream from the radiation source, each absorbs total heat loads $\sim 7 \mathrm{~kW}$ of not used synchrotron light. There are five BPM installed in the

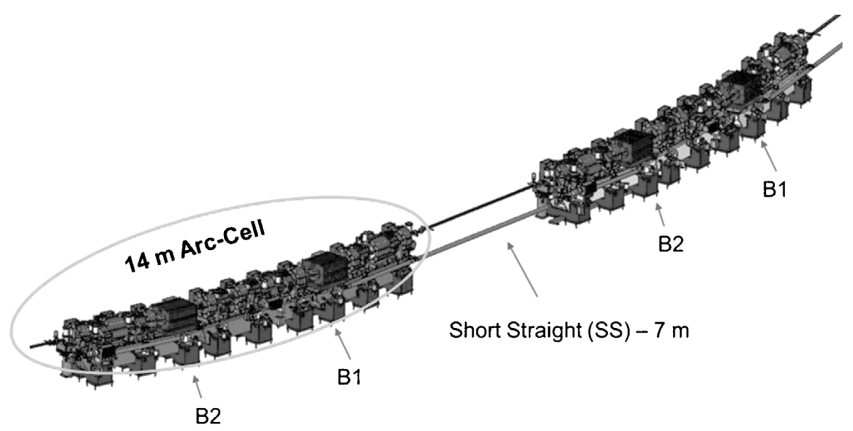

Fig. 1 Layout of the TPS electron-storage ring contains the short straight section and the 14-m arc-cell sections of the 24-DBA lattice.

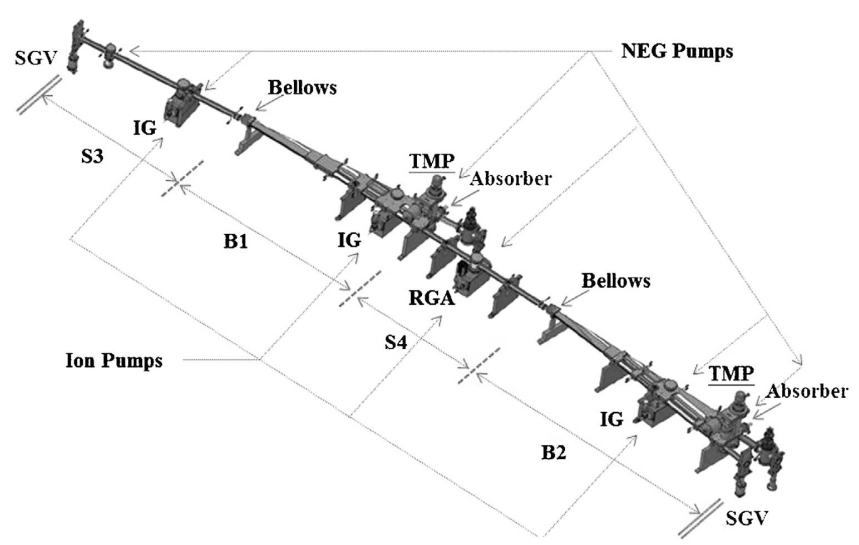

Fig. 2 Schematic drawing of a typical 14-m arc-cell vacuum system. 14-m cell: two on B chambers and 3 on $\mathrm{S}$ chambers; each is composed of two BPM flanges. The strong supports to fix the 14-m-cell vacuum system on the girders are made of precisely machined thick aluminium plates, mostly held tightly on the BPM ducts and damping-supporting other heavy parts, e.g. IP and SGV. The sputtering ion pumps (IP) adopted the commercial Starcell IP and modified the dimensions of the body to fit in the spaces between the magnets. Cartridge-type non-evaporable getter (NEG) pumps were mounted in each IP and the ports near the crotch absorbers to enhance the pumping efficiency for the residual outgassing molecules. Extractor ion gauges (IG) and residual-gas analyzers (RGA) were installed on the side flanges of the IP to measure the total and partial pressures, respectively. Two turbomolecular pumps (TMP) were mounted on each Bchamber near the crotch absorber to pump the significant photon-stimulated desorption (PSD) outgassing from the system during the early commissioning stage, hence decreasing the gas loads on the IP and NEG pumps ${ }^{7}$.

The cross section of the beam ducts of the electron storage ring had to be smooth to decrease the resistivewall and broadband impedances. The number of vacuum components with discontinuous steps or gaps, such as bellows, flanges and pumping holes, was decreased. RF-contact spring fingers were adopted for the bellows and comb fingers for the SGV, of design similar to that at the $\mathrm{KEKB}^{11)}$ accelerator but with modified cross sections, as shown in Fig. 3(a) and 3(b). The RF bridge joining the flanges between the beam ducts was a specially designed thin aluminium plate with a precisely machined knife edge on one side. Figure 3(c) depicts the aluminium plate of a RF bridge connecting between the flanges and the SGV. The flat side of the plate was fixed on the flange of the beam duct; the knife-edge side was in contact on the flange of the SGV that can be depressed during tightening of the flanges. The depth from the peak of the knife edge to the inside edge of flange becomes decreased from $0.5 \mathrm{~mm}$ to $0.2 \mathrm{~mm}$ after depression and the impedance was decreased. The BPM flange, made of stainless steel, contains two electric feedthroughs welded with a laser beam, as shown in Fig. 3(d). Each feedthrough was specially designed to match impedance $50 \Omega$ and to decrease the ratio of reflected power to $<5 \%$, for comparison with a ratio $>20 \%$ of commercial products ${ }^{10)}$. The BPM flange was machined with precise holes for the BPM feedthrough, a tiny pumping channel from each feedthrough hole to the vacuum side, a smooth surface to seal the gasket, a precise contact-alignment structure to position the BPM flange in the BPM duct, and so forth. The clearance, 0.3 $\mathrm{mm}$, between the BPM button and the hole of the BPM flange was well controlled with precision $<30 \mu \mathrm{m}$ for all BPM assemblies, to achieve the quality of low impedance $^{12}$. All BPM flanges had passed a test for thermal shock on immersion in liquid nitrogen $\left(\mathrm{LN}_{2}\right)$ for several cycles between $25^{\circ} \mathrm{C}$ and $-196^{\circ} \mathrm{C}$, without leakage. The BPM ducts (aluminium alloy) were CNCmachined. The surface to seal the gasket was machined 

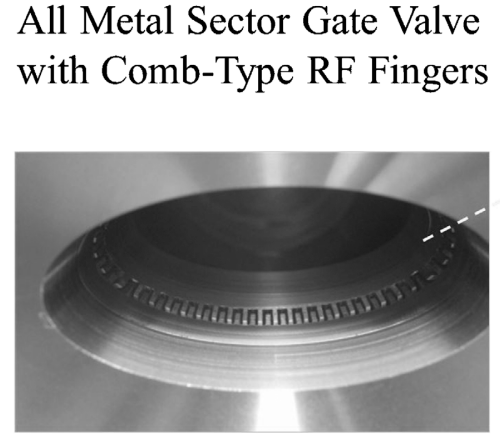

Comb-Type RF Fingers

(a)

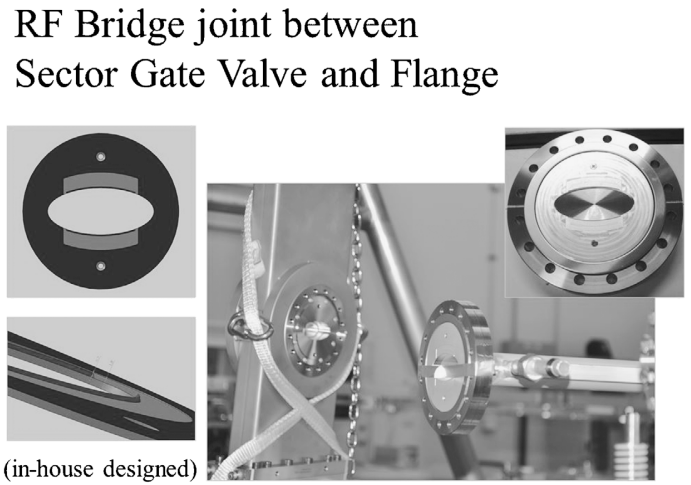

(c)

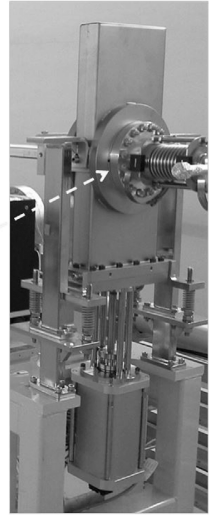

Al/Ti Bellows with RF Fingers

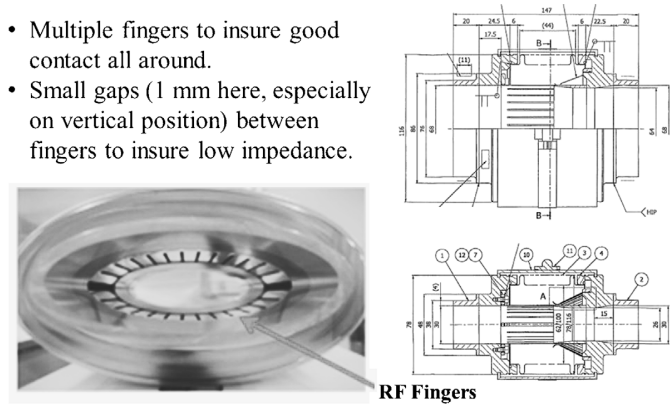

(b)

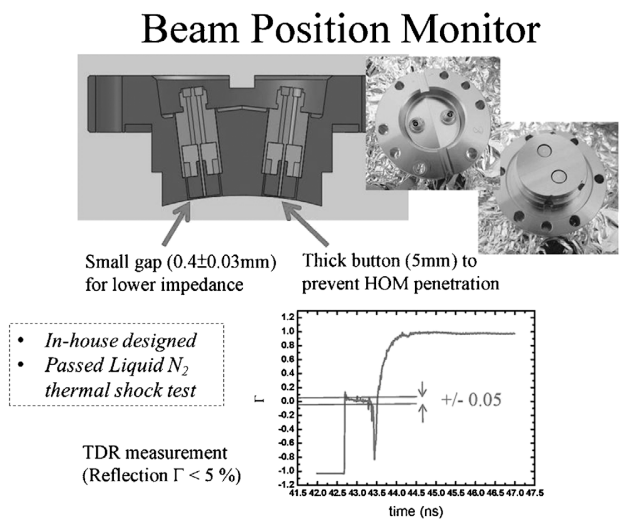

(d)

Fig. 3 Photographs and drawings of critical components of TPS: (a) all-metal sector gate valve (SGV) with the comb fingers, (b) bellows with RF-contact spring-finger, (c) aluminium plate for the RF bridge between the flanges of the beam duct and the SGV, (d) cross-sectional view of the beam- position monitor (BPM-) flange and measured ratio of the reflection.

smoothly with roughness $<0.8 \mu \mathrm{m}$. The specially designed contact-alignment structures on the body of the BPM flanges were precisely machined for positioning to the BPM ducts in the correct orientation. Three BPM ducts were welded in $\mathrm{S} 3$ and $\mathrm{S} 4$ chambers; two BPM are located on B1 and B2 chambers. Each BPM assembly contains a pair of BPM flanges installed on upper and lower flange ports of the BPM ducts or the B chambers. The sealing gasket between the BPM flange and the BPM duct was made of soft aluminium alloy (A1050H14); a knife edge was machined on both sides similar to a diamond shape. When the BPM flange is tightened onto the BPM duct, the so-called diamond-edge gasket becomes depressed and forms a vacuum seal ${ }^{13)}$.

\section{Manufacturing of the 14-m aluminium UHV sys- tems completely free of oil}

The pressure in the beam duct of the electron-storage ring must be maintained under $100 \mathrm{nPa}$ at all times, including when the stored beam current is maximum at 500 $\mathrm{mA}$. Because of the limited pumping conductance of the beam ducts, the outgassing molecules in the beam ducts are difficult to eliminate. The rate of thermal outgassing of the surfaces in the beam ducts must be less than 1.0 $10^{-10} \mathrm{~Pa} \mathrm{~m} \mathrm{~s}^{-1}\left(0.1 \mathrm{nPa} \mathrm{m} \mathrm{s}^{-1}\right)$ without a beam (static vacuum). The increase of dynamic pressure from the photon-stimulated desorption (PSD) during the beam operation (dynamic vacuum) must be $<0.2 \mathrm{nPa} \mathrm{mA}^{-1}$. A manufacturing process completely free of oil developed for the large B chambers was proved to fulfill this requirement ${ }^{14)}$. The manufacture of the 14-m-cell vacuum systems is described in the following sections.

\subsection{CNC machining free of oil and cleaning with ozonized water}

The large aluminium plates for the 4-m B chambers were precisely machined with a computer-numericalcontrol (CNC) machine in a clean room (class 10,000); the temperature was maintained at $25 \pm 11^{\circ} \mathrm{C}$, and relative humidity $<50 \%$ to avoid thermal expansion of the material and to slow the oxidation of the machined surface. Pure ethanol sprayed with super-dry compressed air was applied to the surface throughout the machining, which not only cooled the materials but also slowly generated clean oxide layers. All tools were cleaned without oil before the machining work. The total machining was divided into three steps: rough machining to $<0.5 \mathrm{~mm}$, intermediate machining to $<0.2 \mathrm{~mm}$, and precise machining to $<0.05 \mathrm{~mm}$, with $1 \sim 3$ days between steps to relax the stress. Figure 4 illustrates the facility of the ethanol-machining work in the clean room for the large Al plates of the B chambers. The dimensions and flatness of the plate were inspected with dial gauges on the platform of the $\mathrm{CNC}$ machine, which adopted the same references of alignment. The machined 


\section{CNC Machining Processes (sprayed with pure alcohol) for 3 Types of B Chambers}

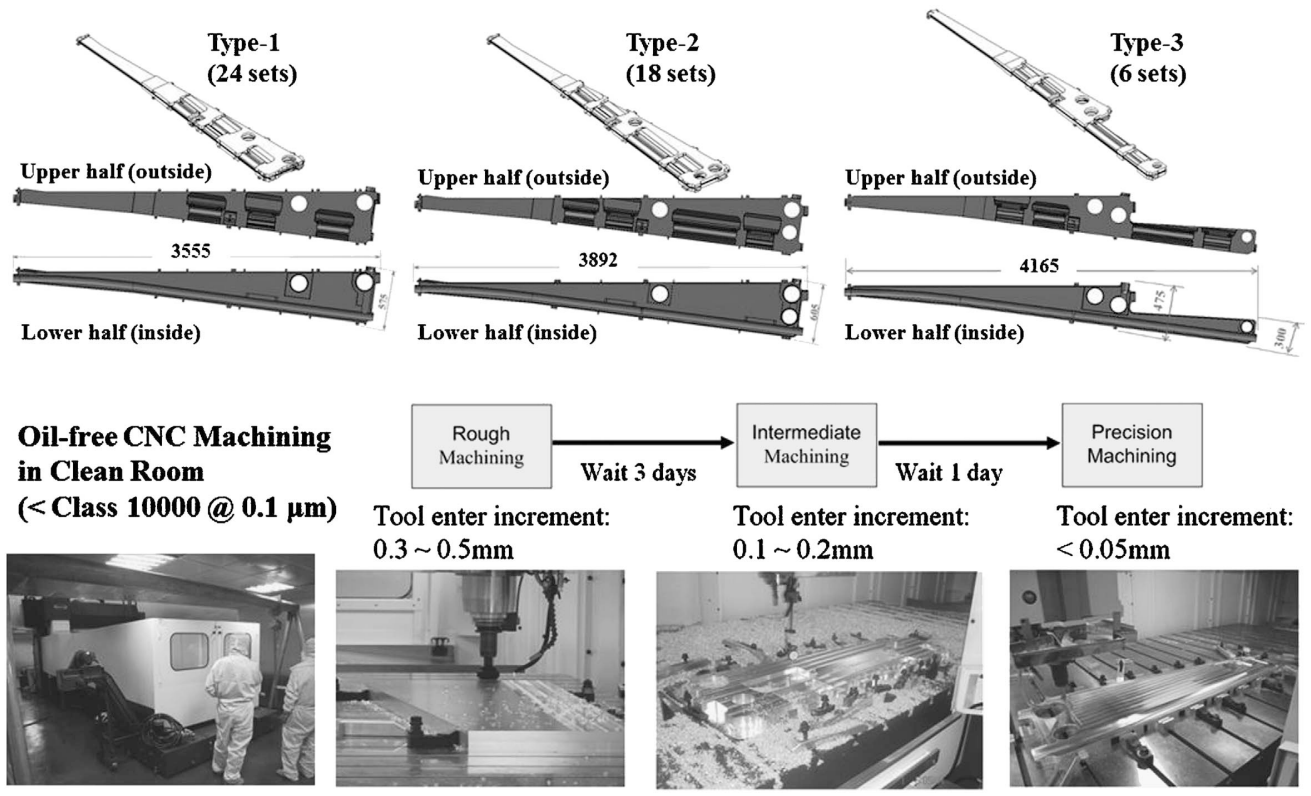

Fig. 4 Facility of the ethanol CNC machining work in the clean room for the large aluminium plates for B chambers of various kinds.

plate was then packed and sealed in a large aluminium bag filled with dry nitrogen gas, deoxidizer and dryer, and delivered to the laboratory of NSRRC. Further cleaning with ozonized water was applied to the Al plates before welding. A commercial generator produced the ozonized water (concentration $>20 \mathrm{ppm}$ ) in a large vessel for immersion of the $\mathrm{Al}$ plate about $30 \mathrm{~min}$. The plate was immediately sent to the cleaning room for welding. The rate of thermal outgassing for the aluminium chambers produced with ethanol-CNC machining followed with cleaning with ozonized water was measured to be less than $0.01 \mathrm{nPa} \mathrm{m} \mathrm{s}^{-1}$ after baking at $150^{\circ} \mathrm{C}$ for 24 $\mathrm{h}^{14)}$.

\subsection{Six-torch automatic TIG welding system}

The aluminium $\mathrm{B}$ chambers were produced on welding the two halves of the aluminium (Al) plates with the tungsten-inert-gas (TIG) welding process. All welding work was performed in a class- 1000 clean room with temperature well controlled at $25 \pm 1^{\circ} \mathrm{C}$ and humidity $<50 \%$. The two Al plates, after the pumping ports were welded on each one, were combined face to face and temporarily welded together. The assembly was then moved to a platform to weld the longitudinal sides. A six-torch automatic TIG welding system established to weld simultaneously both long sides of the B chamber achieved not only a reliable quality of welding but also the least deformation. Three pairs of welding-torch assemblies were placed on both non-parallel straight sides of the B chamber, three fixed torches to weld one side and three motorcontrolled torches to weld the opposite side. Those torches were ignited simultaneously when the B chamber was moved along a longitudinal axis perpendicular to the torches. The oxide layer on the aluminium surface had to be eliminated before the welding; the chamber was heated to $\sim 90^{\circ} \mathrm{C}$ throughout the period of auto-welding. Figure 5 shows a drawing of the auto TIG welding sys- tem and photographs of welding the $\mathrm{B}$ chamber ${ }^{8)}$. The dimensions of the $\mathrm{B}$ chamber after welding showed overall flatness $<0.1 \mathrm{~mm}$ in the vertical direction and straightness $<0.3 \mathrm{~mm}$ in the horizontal direction. The remaining parts of the $\mathrm{B}$ chamber were subsequently welded by hand. B chambers of all three types, 48 in total, passed the test of leakage $<0.1 \mathrm{nPa} \mathrm{m}^{3} \mathrm{~s}^{-1}$ with a leak detector.

\subsection{Assembly of the 14-m-cell UHV system and baking ex situ}

As soon as the four beam ducts, S3-B1-S4-B2, for one 14-m arc cell had been prepared, they were moved to the girders and fixed on the supports that had been aligned within $<0.1 \mathrm{~mm}$. The four beam ducts were then welded in series to form one segment of a 14-m unit cell. All vacuum components for a cell, including the BPM flanges, vacuum pumps, valves and gauges, were installed directly after welding. Because of the tardy delivery of the crotch absorbers and the photon stoppers from the vendors, each 14-m cell had to be temporarily sealed in vacuum and moved from the girders to a storage area. To protect the straightness of the 14-m aluminium chambers from distortion or damage, aluminium jigs and frames in 24 sets were manufactured to hold the 14-m-cell vacuum system during the entire period until removal to the destination in the tunnel. Several assemblies of hanger were made to convey the 14-m-cell vacuum systems on leaving the girder supports. A storage area near the assembly room provided a clean space with temporary posts to anchor the 24 vacuum cells, awaiting the installation of absorbers and photon stoppers, and baking. Each 14-m-cell vacuum system was baked to $150^{\circ} \mathrm{C}$ for $24 \mathrm{~h}$ to attain the UHV. A typical ultimate pressure $\sim 6.4 \mathrm{nPa}$ was achieved after baking ${ }^{15)}$, but some leakage was found after baking of many cells. The leakage that occurred to the 24 cells through the 


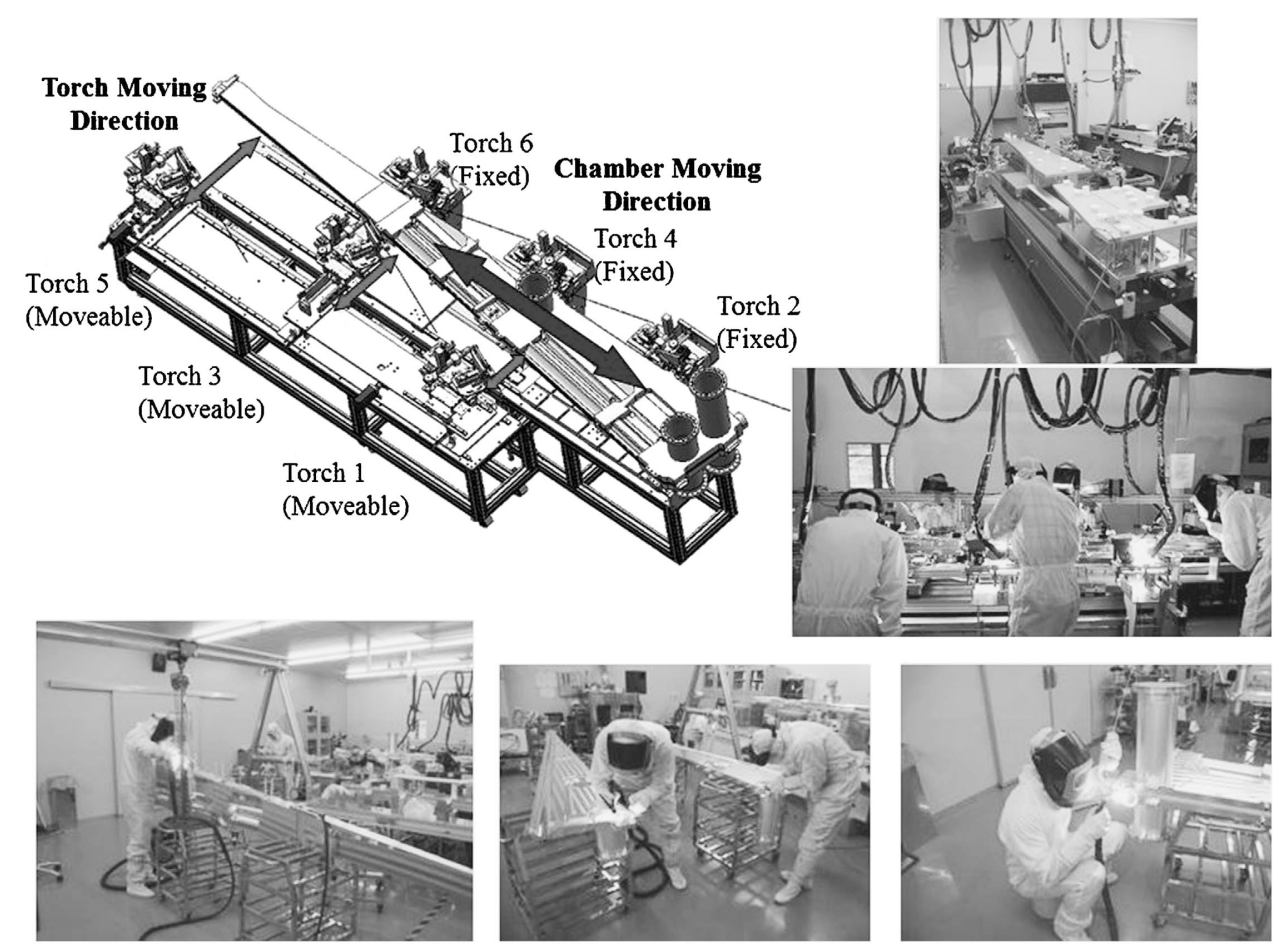

Fig. 5 Schematic drawing of the auto TIG welding system and the photographs of welding of the B chamber in the clean room.

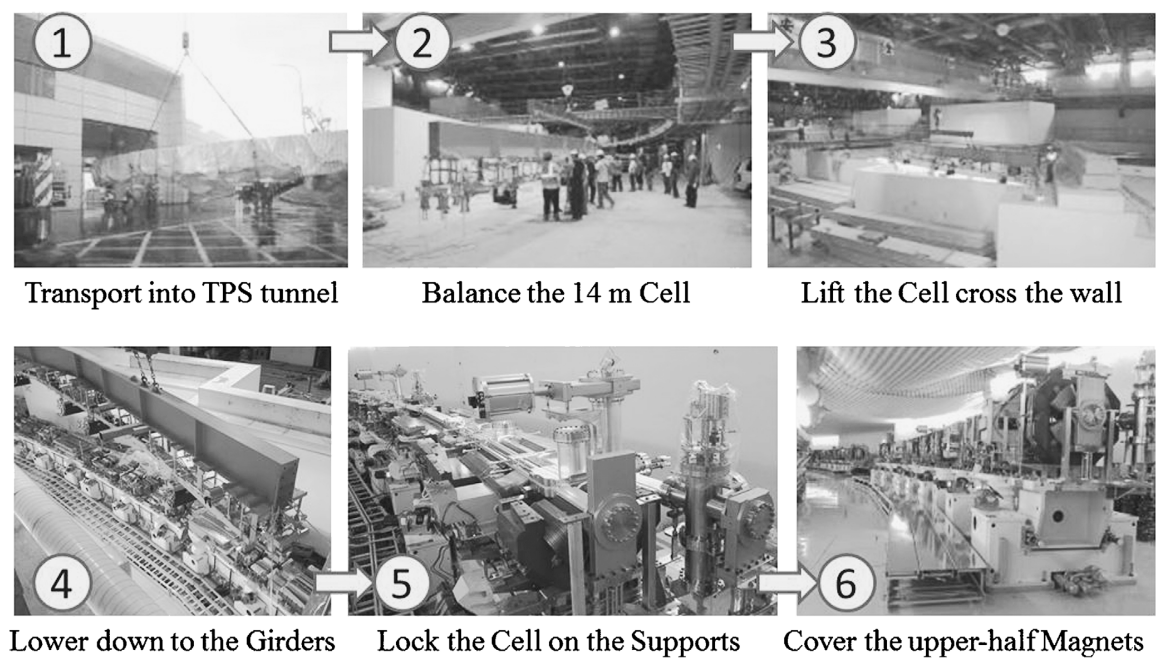

Fig. 6 Photographs concerning the transport and installation of the 14-m-cell vacuum system from the laboratory to the TPS tunnel.

baking histories included 11 occurrences of leaks from bimetal flanges, 16 occurrences of leaks from BPM flanges, 8 occurrences of leaks from the BPM feedthrough, three occurrences of leaks from the ion-gauge feedthrough, two occurrences of leaks from the metal angle valves, one occurrence of a leak from a brazed joint, and one occurrence of a leak from a welded joint. A period 10.5 months elapsed during the baking of the 24 cells, of which only 11 cells passed the baking once without leakage, six cells were baked twice, and seven cells were baked three to six cycles until the UHV was acceptable and leak-tight ${ }^{16)}$.

\subsection{Quick installation of 24 cells in the TPS tunnel}

Baking the 24 cells of the 14-m vacuum systems ex situ solved the leakage problems and achieved the UHV in the laboratory. The 14-m-cell vacuum systems had then to be transported to the TPS tunnel and installed quickly, not only to save the working hours in the tunnel but also to ensure the vacuum quality after installation. When the civil construction of the TPS tunnel was finished and girders with magnets for the 24 cells were installed and aligned, the 14-m-cell vacuum systems could then be installed. Before the installation of each assembly, the upper halves of the magnets were dismounted; the 14-m cell was carried by the hanger, transported to the TPS tunnel, lifted with the overhead crane and moved to the girders above the magnets, then lowered slowly to the supports and fixed. Figure 6 comprises photographs about the transport and installation of the 14 -m-cell vacuum system from the laboratory to the TPS 


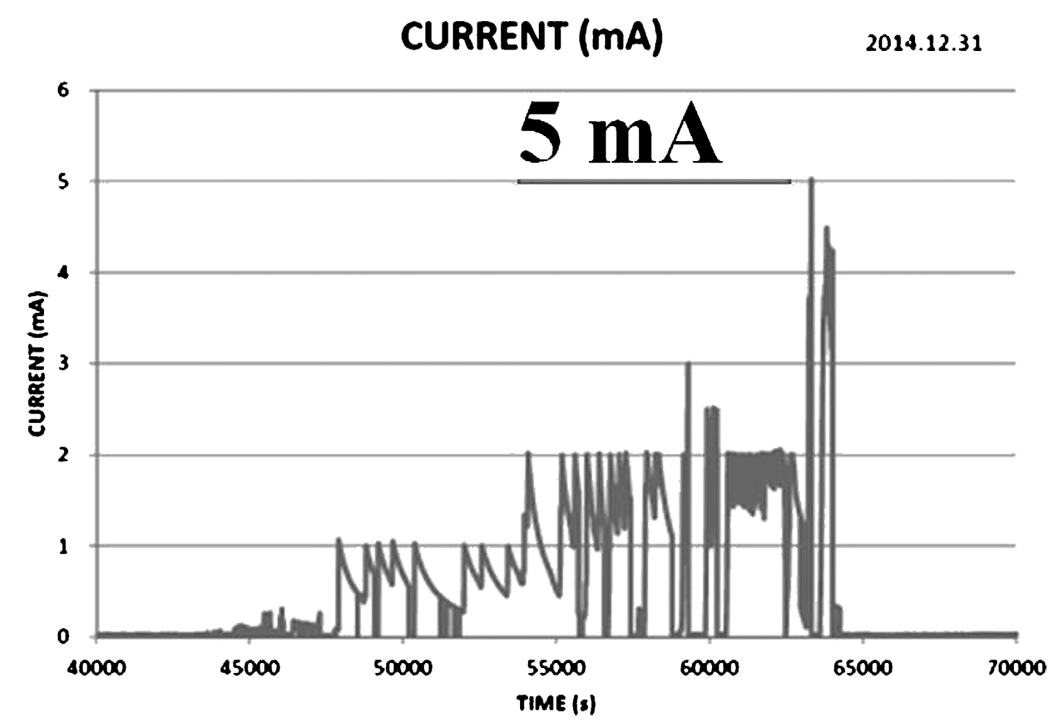

Fig. 7 Beam injection into the storage ring and stored, when the first synchrotron light was observed, on 2014 December 31 . The maximum current attained was $5 \mathrm{~mA}$.

tunnel, which took about four working hours ${ }^{16)}$. The jigs for the chambers were removed and the upper halves of those magnets were recovered on the next day. The continued installation of 18 cell-vacuum systems to the site of the TPS tunnel took three months in total. Other vacuum cells awaited the alignment of the remaining girders and magnets. Installation of the vacuum systems for the 24 long straight sections was executed directly after the two cells on both ends had been loaded, which proceeded more easily because of the simpler structure for quick assembly on site and baking in situ as well. The connections of the cables from the control and instrument area (CIA) and the cooling tubes from the utility supply systems to the SR vacuum systems continued to operate in parallel with the installation and baking of the vacuum systems in the long straight sections of SR, the BR and the transport lines. All that work, which occupied about half a year, finished in 2014 August.

\section{Commissioning of the TPS vacuum system}

The commissioning of TPS began in 2014 August with testing the 3-GeV full-energy injections of the BR and the transport lines. The electron beam at energy 150 $\mathrm{MeV}$ was extracted from the LINAC to the BR by $\mathrm{Au}-$ gust 14. In commissioning the BR, the multi-turn was achieved and the beam was captured with RF on September 16, but with a large loss of beam. Optimization of the orbit control and the launching condition continued but the elliptical thin-wall beam ducts for the BR magnets were found not to be de-magnetized, which resulted in problems of beam control. All thin-wall beam ducts were disassembled from the BR and sent to the factory for de-magnetization, then replaced at the $\mathrm{BR}$ and baked. All repair work required three weeks in 2014 November. Afterwards, commissioning of the BR was restored, which enabled the extraction of the $3-\mathrm{GeV}$ electron beam and injection through the BTS to the SR in December to achieve the full energy injection. As soon as the electron beam was injected into the SR, the first synchrotron light was observed; the stored current attained $5 \mathrm{~mA}$ on 2014 December 31, as shown in Fig. 7.

During continued commissioning in 2015 , the objective was to increase the beam current and to maintain the top-up injection mode to enhance the efficiency of the beam cleaning that facilitated the outgassing through photon-stimulated desorption (PSD) from the absorbers. The increased beam current was, however, subject to the constraint of a radiation level $<2 \mu \mathrm{Sv}$ accumulated in four hours and a pressure $<10,000 \mathrm{nPa}\left(<1 \times 10^{-7}\right.$ mbar). The temperature sensors mounted on the noncooled parts downstream from the absorbers, e.g. the bellows, monitored the increased temperature $<35^{\circ} \mathrm{C}$ before triggering the alarm system. After the first three months of commissioning in 2015, the stored beam current was increased to $100 \mathrm{~mA}$, with lifetime six hours and average pressure $120 \mathrm{nPa}$, at accumulated beam dose 33 ampere hours ( $\mathrm{A} \mathrm{h}$ ). Figure 8 illustrates the archived history of the data in the last few days of 2015 March. A typical mass spectrum measured with a residual-gas analyzer (RGA) in the SR, shown in Fig. 9, illustrates the major residual gases to be $\mathrm{H}_{2}(60 \%), \mathrm{CH}_{4}(23 \%), \mathrm{CO}$ $(12 \%)$, and $\mathrm{CO}_{2}(5 \%)$. After shutdown for 6.5 months, the subsequent commissioning resumed in September, which quickly increased in one month the beam current to $200 \mathrm{~mA}$ with lifetime $2 \mathrm{~h}$ at beam dose $100 \mathrm{~A} \mathrm{~h}$. The average pressure normalized to the beam current $(\mathrm{dP} / \mathrm{I})$ was decreased to $0.4 \mathrm{nPa} \mathrm{mA}^{-1}$, from $120 \mathrm{nPa} \mathrm{mA}^{-1}$ at the beginning and diminished to $1.2 \mathrm{nPa} \mathrm{mA}^{-1}$ at the end of March. Figure 10 shows curves of the trend of the dynamic pressure and the products of current and lifetime in four months of efficient commissioning. The dynamic pressure was near the simulated result ${ }^{17}$.

\section{Conclusion}

Commissioning of the TPS was initiated in $2014 \mathrm{Au}-$ gust; the first synchrotron light was successfully extract- 


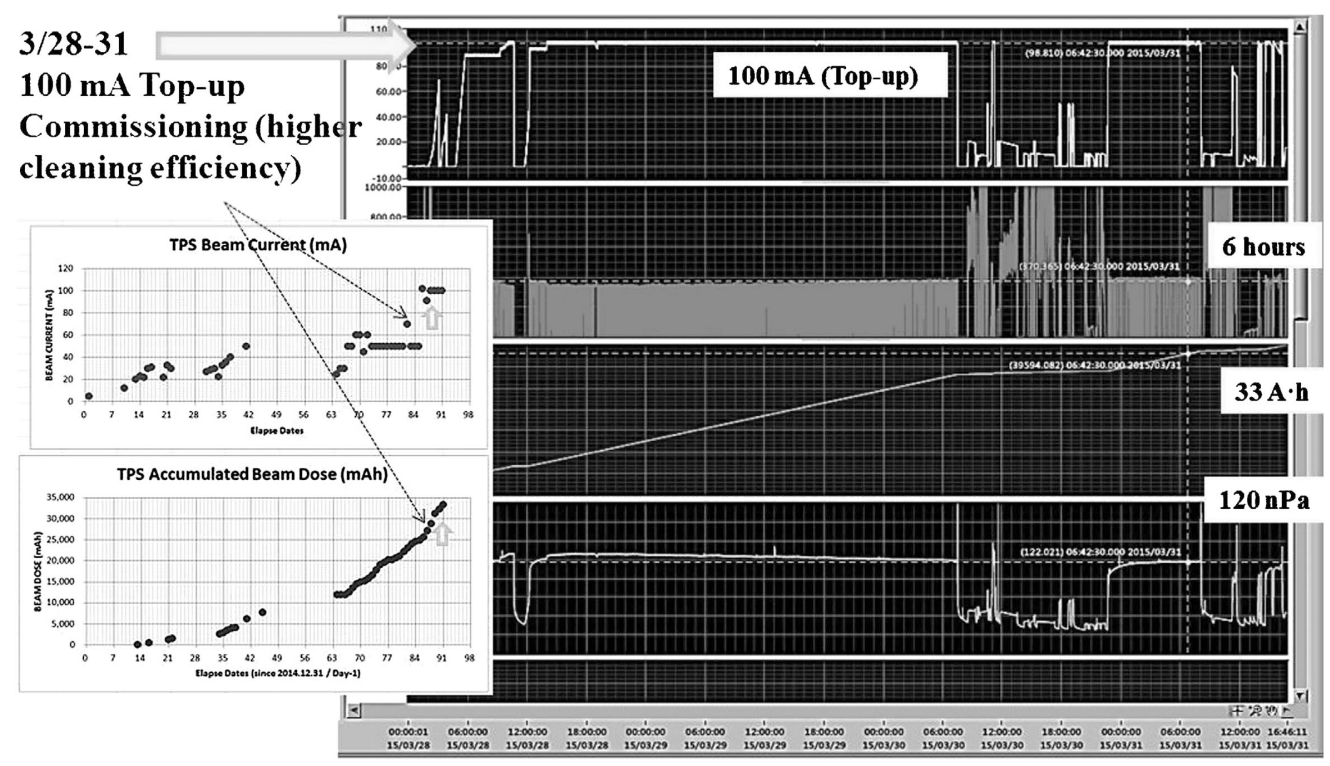

Fig. 8 History of data archived in the last few days of 2015 March shows the beam current stored at $100 \mathrm{~mA}$ (top-up) with lifetime $6 \mathrm{~h}$, average pressure $120 \mathrm{nPa}$, at accumulated beam dose $33 \mathrm{~A} \mathrm{~h}$.

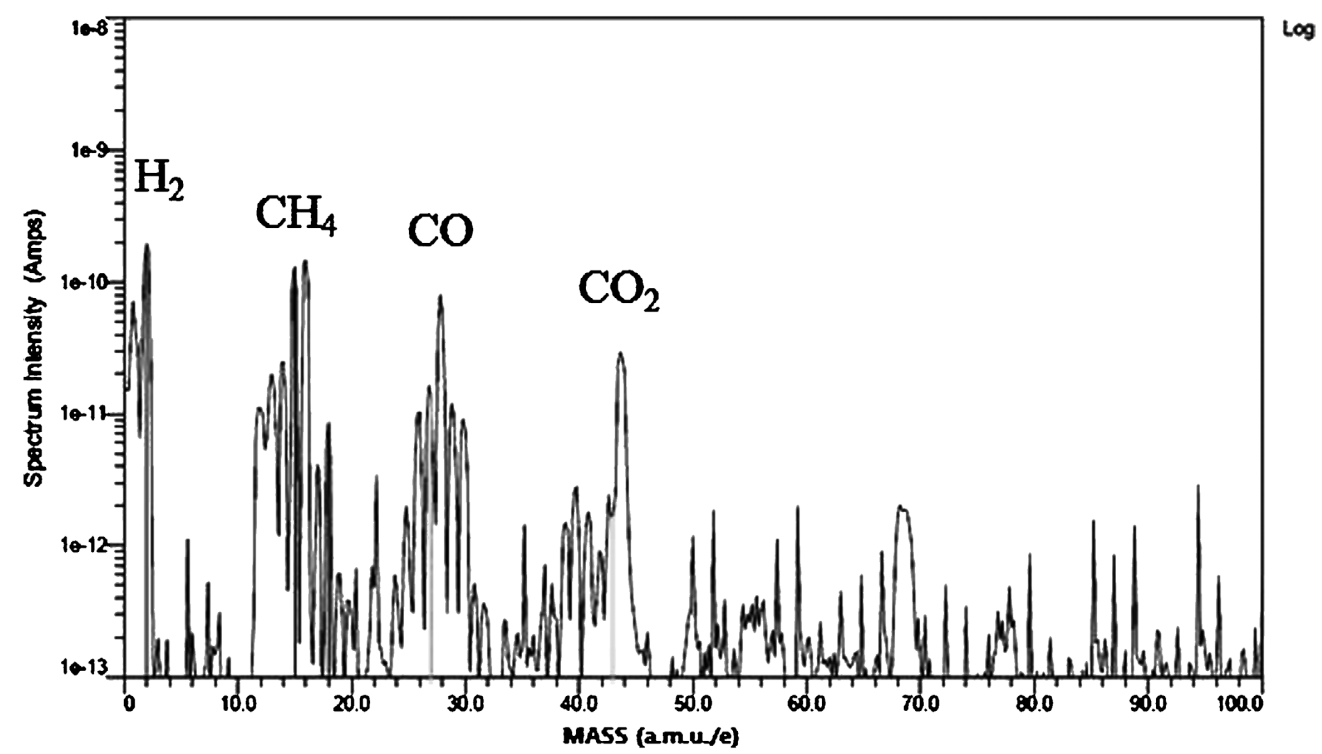

Fig. 9 Typical mass spectrum measured with a residual-gas analyzer (RGA) in the SR illustrates that the major residual gases comprised hydrogen $\left(\mathrm{H}_{2}\right)$, methane $\left(\mathrm{CH}_{4}\right)$, carbon oxide $(\mathrm{CO})$ and carbon dioxide $\left(\mathrm{CO}_{2}\right)$.

ed on 2014 December 31. Commissioning continued in 2015 for four months in total to achieve the $3-\mathrm{GeV}$ fullenergy injection and a stored electron beam $200 \mathrm{~mA}$ in top-up mode with lifetime $2 \mathrm{~h}$. The accumulated beam dose $100 \mathrm{~A} h$ was achieved and the dynamic pressure was decreased from $120 \mathrm{nPa} \mathrm{mA}^{-1}$ to $0.4 \mathrm{nPa} \mathrm{mA}^{-1}$ (or $4 \times$ $\left.10^{-12} \mathrm{mbar}_{\mathrm{mA}}^{-1}\right)$. The concept involving the preparation of 24 cells of 14-m aluminium ultrahigh-vacuum systems for an electron-storage ring of TPS was unique. It relied on precise $\mathrm{CNC}$ machining completely free of oil in a clean room to maintain the clean surfaces. Cleaning with ozonized water was applied to the pre-cleaned surface of the aluminium B chambers to decrease further the rate of surface outgassing, to become less than 0.01

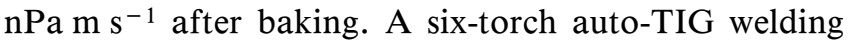

system was established to weld the 4-m large aluminium bending chamber to obtain the deformation at least smaller than $0.3 \mathrm{~mm}$. The chambers in a $14-\mathrm{m}$ vacuum system were welded into one piece so that the quantity of bellows and flanges was decreased, consequently lowering the impedance of the chamber. Baking of the 14-m vacuum system performed ex situ in the laboratory achieved the UHV quality after solving the leakage problems before the installation. A precise heavy-loading carrier was constructed to hang the 14-m vacuum system from the storage area for transport to the tunnel site for the installation, which took about half a day. Critical components with small impedance, e.g. BPM flanges, bellows with RF contact, gate valves with comb-type finger, and the RF bridge for the flanges, were developed to 


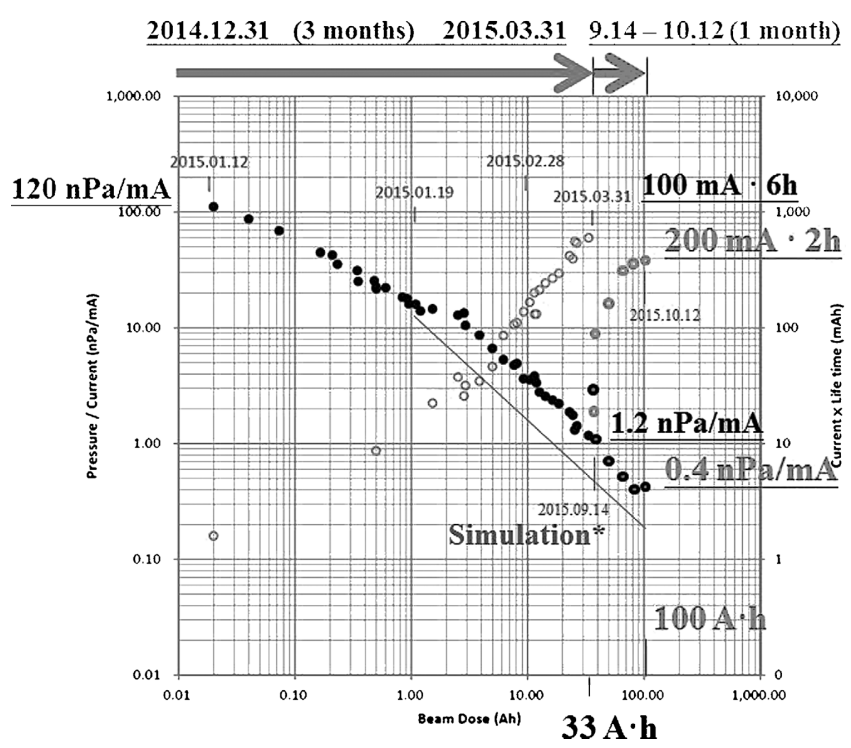

Fig. 10 Curves of the trends of dynamic pressure (black dots) and products of beam current and lifetime (red circles) in four months of commissioning.

achieve a decreased impedance of the beam ducts for TPS. The manufacture of the 14-m aluminium UHV systems in 24 sets completely free of oil revealed the highest quality of precision, reliability and vacuum performance of the accelerator light source, which resulted in a highly efficient commissioning and rapid achievement of the goals for TPS.

\section{Acknowledgements}

This paper is written on behalf of the entire TPS vacuum group. I thank all members of this group for their hearty collaboration in developmental and manufacturing work for the high-quality vacuum chambers and components of the 14-m aluminium ultrahigh-vacuum systems, and the highly efficient installation of these vacuum systems to compose the TPS accelerator.

\section{References}

1) C. C. Kuo, H. P. Chang, P. J. Chou, H. C. Chao, W. T. Liu, G. H. Luo, H. J. Tsai, J. W. Tsai, A. Rusanov and K. Liang: Proc. EPAC08, Genoa, Itary, WEPC004 (2008) 1986.
2) C. C. Kuo, J. Y. Chen, M. S. Chiu, P. J. Chou, Y. C. Liu, H. J. Tsai, F. H. Tseng, K. T. Hsu, G. H. Luo and C. T. Chen: Proc. IPAC2015, Richmond, USA, TUXC3 (2015) 1314.

3) G. Y. Hsiung, C. K. Chan, C. C. Chang, H. P. Hsueh, Z. D. Tsai and J. R. Chen: Proc. EPAC08, Genoa, Itary, THPP143 (2008) 3699.

4) G. Y. Hsiung, C. K. Chan, C. H. Chang, H. P. Hsueh, T. L. Yang and J. R. Chen: Proc. EPAC06, Edinburgh, UK, THPLS064 (2006) 3433.

5) G. Y. Hsiung, C. K. Chan, H. P. Hsueh, T. L. Yang, C. K. Kuan, C. C. Chang, S. N. Hsu, C. Y. Yang, C. L. Chen and J. R. Chen: Syn. Rad. Instru. Daegu, Korea, CP879 (2007) 62.

6) J. R. Chen, G. Y. Hsiung, C. K. Chan, T. L. Yang, C. K. Kuan, S. N. Hsu, C. C. Chang, J. Y. Yang, H. P. Hsueh and C. L. Chen: J. Vac. Soc. Jpn., 49 (2006) 12.

7) G. Y. Hsiung, C. K. Chan, C. C. Chang, C. L. Chen, S. N. Hsu, H. P. Hsueh, A. Sheng, C. Y. Yang, Y. B. Chen and J. R. Chen: Proc. PAC09, Vancouver, Canada, MO6RFP018 (2009) 387.

8) J. R. Chen, G. Y. Hsiung, C. C. Chang, C. L. Chen, C. K. Chan, C. M. Cheng, C. Y. Yang, L. H. Wu and H. P. Hsueh: J. Vac. Sci. Technol. A, 28 (4) (2010) 942.

9) C. K. Chan, G. Y. Hsiung, C. C. Chang, Rouge Chen, C. Y. Yang, C. L. Chen, H. P. Hsueh, S. N. Hsu, Ivan Liu and J. R. Chen: J. Phys. Conf. Series, 100 (2008) 092025.

10) I. T. Huang, H. P. Hsueh, C. L. Chen, C. C. Chang, G. Y. Hsiung and J. R. Chen: Proc. IPAC2011, San Sebastian, Spain, TUPS029 (2011) 1593.

11) Y. Suetsugu, K. Kanazawa, N. Ohuchi, K. Shibata and M. Shirai: Proc. PAC05, Knoxville, USA, RPPE052 (2005) 3203.

12) H. P. Hsueh, I. T. Huang, C. C. Chang, S. N. Hsu, G. Y. Hsiung and J. R. Chen: Diamond Light Source Proceedings of MEDSI-6, Oxfordshire, UK, 2010, 1 (Diamond Light Source Ltd, UK, 2011), e56, p. 1 .

13) I. T. Huang, C. C. Chang, H. P. Hsueh, C. L. Chen, G. Y. Hsiung and J. R. Chen: Proc. IPAC2012, New Orleans, USA, WEPPD023 (2012) 2549.

14) G. Y. Hsiung, C. K. Chan, C. C. Chang, Y.B. Chen, H. P. Hsueh, C. L. Chen, C. Y. Yang, S. N. Shu, C. M. Cheng, C. K. Kuan, I. C. Sheng and J. R. Chen: J. Phys. Conf. Series, 100 (2008) 092014.

15) L. H. Wu, T. Y. Lee, G. Y. Hsiung, Y. C. Yang, Z. W. Chen, Y. P. Chang, C. S. Huang, Y. T. Huang, C. H. Chang, S. W. Chang, C. C. Chang, S. N. Hsu, Y. T. Cheng, C. K. Chan, C. M. Cheng, B. Y. Chen, H. P. Hsueh and J. R. Chen: Vacuum, 109 (2014) 368.

16) G. Y. Hsiung, H. P. Hsueh, L. H. Wu, C. C. Chang, C. M. Cheng, C. K. Chan, Y. C. Yang, T. Y. Lee, C. S. Huang, C. H. Chang, I. T. Huang, S. W. Chang, S. N. Hsu and J. R. Chen: Vacuum, 121 (2015) 245.

17) G. Y. Hsiung, C. K. Chan and J. R. Chen: Vacuum, 86 (2012) 1688. 